\title{
Ascending aorta-right pulmonary artery anastomosis: Waterston's operation
}

\author{
F. A L V A REZ-DíAZ, J.M. B RITO, G. COR D OVILLA,
} J. PEREZ DE LEÓN, P. A. SANCHEZ, and C. M. BORDIÚ

Department of Surgery, University Hospital 'Ciudad Sanitaria La Paz', Children's Hospital, Madrid, Spain

The results of 180 cases of congenital heart disease with diminished pulmonary flow operated upon with Waterston's technique are presented.

It is considered that Waterston's operation is to be preferred in children under 2 years of age and in older children who have had a previous thrombotic or insufficient Blalock operation and in whom total correction is not indicated.

The problem of pseudotruncus with hypoplastic pulmonary arteries is discussed. The convenience of the Waterston operation in these cases, and the importance of creating an anastomosis at the pulmonary bifurcation and as far back as possible in the aorta, is emphasized.

The need to perform this technique in the correct way is stressed. This will avoid the kinking and pulling of the right pulmonary artery, which are causes of preferential blood flow to the right lung, as we have demonstrated experimentally.

The possible complications caused by such a technical failure are discussed. The necessity for previous angiocardiographic study, in order properly to repair the defect during total correction, is also considered.

The technique of ascending aorta-right pulmonary artery anastomosis was described by Waterston in 1962. The creation of this pulmonary systemic fistula is especially indicated in infants and in older children with cyanotic heart disease with a low pulmonary flow and a short or narrow subclavian artery. In these cases, the results of a BlalockTaussig operation are poor owing to reduced blood flow or thrombosis of the fistula.

Because of the increasing popularity of this technique, a large number of reports have recently been published (Cooley and Hallman, 1966; Edwards, Mohtashemi, and Holdefer, 1966 ; Waldhausen et al., 1968 ; Somerville, Yacoub, Ross, and Ross, 1969 ; Pickering, Trusler, Lipton, and Keith, 1971).

\section{CLINICAL MATERIAL}

We present our experience with 180 patients operated upon during the period 1968-71.

The ages of the patients ranged from 6 days to 5 years ; $42.5 \%$ of the children were less than 1 year old. Two patients were aged 15 and 18 years; one had had an insufficient Blalock operation and in the other the fistula had thrombosed.

Table I shows the distribution of cases according to diagnosis.
T A B L E I

\begin{tabular}{l|c|cccc}
\hline \multirow{2}{*}{ Diagnosis } & \multirow{2}{*}{$\begin{array}{c}\text { No. of } \\
\text { Cases }\end{array}$} & \multicolumn{4}{|c}{ Mortality } \\
\cline { 3 - 7 } & Early & Late & Total & $\%$ \\
\hline Fallot's tetralogy & 109 & 1 & 4 & 5 & $4 \cdot 5$ \\
Pseudotruncus & 19 & 7 & 2 & 9 & 48 \\
Tricuspid atresia & 20 & 2 & 4 & 6 & 30 \\
Pulmonary atresia & 8 & 1 & & 1 & 12 \\
Miscellaneous anomalies & 24 & 5 & & 5 & 22 \\
\hline \multicolumn{1}{c}{ Total } & 180 & 16 & 10 & 26 & $14 \cdot 4$ \\
\hline
\end{tabular}

SURGICAL INDICATIONS At present we use the operation in the following cases:

(a) severe hypoxaemia with arterial saturation less than $50 \%$ and severe metabolic acidosis $(55 \%$ of our cases) ;

(b) hypoxaemia and enlarged liver $(21 \%)$;

(c) retarded growth $\left(20_{0}^{\circ}\right)$;

(d) obstructed previous Blalock operation $(4 \%)$.

CHOICE OF TECHNIQUE Table II shows the choice of technique in each case. In all patients under the age of 2 years we used Waterston's technique, if the venous collateral vasculature in the mediastinum was normal or poorly developed. The technique of WaterstonCooley was used if the venous collateral circulation in the mediastinum was well developed. We also used the 
T A B L E I I

CHOICE OF PALLIATIVE TECHNIQUE

\begin{tabular}{|c|c|}
\hline $\begin{array}{l}\text { Less than } 2 \text { years of age: } \\
\text { (a) Norma l collateral circulation } \\
\text { in mediastinum } \\
\text { (b) Increased collateral circula- } \\
\text { tion in mediastinum and } \\
\text { severely sick patients }\end{array}$ & $\begin{array}{l}\text { Waterston } \\
\text { Waterston-Cooley }\end{array}$ \\
\hline $\begin{array}{l}\text { Over } 2 \text { years of age: } \\
\text { (a) Subclavian artery of good } \\
\text { size .. } \\
\text { (b) Reoperation for thrombosis } \\
\text { of Blalock-Taussig .. }\end{array}$ & $\begin{array}{l}\text { Blalock-intrapericardial } \\
\text { (Soloviev) or } \\
\text { Blalock-Taussig } \\
\text { Waterston }\end{array}$ \\
\hline
\end{tabular}

latter operation in the very severe cases, because it can be performed quickly.

In patients over the age of 2 years with a subclavian artery of good size, we used a Blalock-Taussig or Soloviev (intrapericardial Blalock) technique. A Waterston operation was performed in all patients in whom a reoperation was required owing to thrombosis or insufficiency of a previous Blalock operation.

SURGICAL TECHNIQUE A right lateral thoracotomy through the fourth intercostal space was performed. The azygos vein was tied and sectioned. The superior vena cava was dissected and moved aside. The right pulmonary artery was widely dissected to its junction, temporarily occluding the distal end of the artery. The pericardium was opened 3 to $4 \mathrm{~cm}$ by the ascending aorta ; a clamp was placed simultaneously on the aorta and the right pulmonary artery, making a lateral to lateral anastomosis with a continuous $5-0$ suture.

In 1965-66 this operation was modified by Edwards et al. (1966) and Cooley and Hallman (1966). They reached the right pulmonary artery between the superior vena cava and the aorta, making a $6 \mathrm{~cm}$ vertical opening of the pericardium at this level (Fig. 1).

This method has the advantage that it is quicker, especially in patients with a large venous collateral

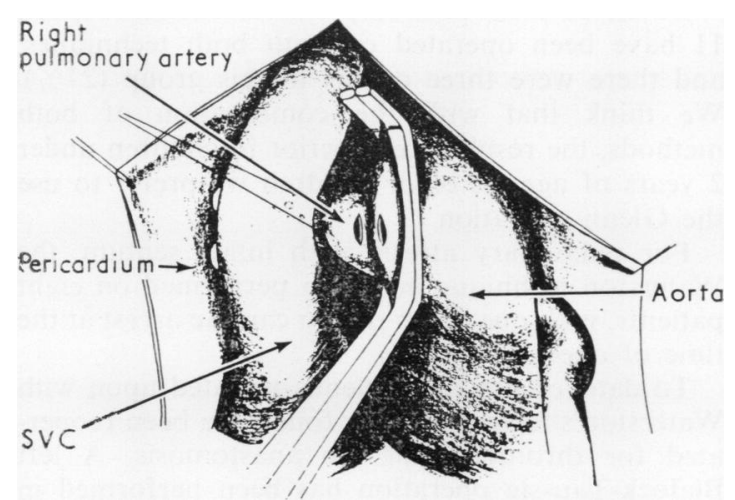

FIG. 1. Edwards-Cooley modification of the Waterston technique. circulation, in whom the dissection might be difficult. However, it has the disadvantage that it makes a wide opening into the pericardium which causes adhesions, a problem at the time of total correction. On the other hand, it is more difficult to perform the anastomosis in the posterior wall of the aorta owing to the risk of kinking of the right pulmonary artery at the level of the anastomosis.

The anastomosis should be made in the posterior wall of the aorta, trying not to kink it at the moment of positioning the clamp, in order to avoid narrowing of the pulmonary artery.

It is very important that the size of the anastomosis should be correct, depending in every case on the age of the patient. In children under 1 year old, we do an anastomosis of 2-3 mm in length, between 1 and 3 years $3-4 \mathrm{~mm}$, and over 3 years $4-5 \mathrm{~mm}$.

\section{RESULTS}

We consider the results of Waterston's technique to be very satisfactory. Among the 180 cases operated upon are included patients under 2 years of age, and older children in an acute condition or with an insufficient or thrombotic Blalock operation, in whom total correction was not indicated. Included also are critically ill patients with repeated cyanotic spells or with very severe metabolic acidosis (Figs 2 and 3). The cases have been classified into five groups as shown in Table $I$.

The causes of immediate and late mortality are specified in Tables III and IV. The highest mortality $(48 \%)$ is related to pseudotruncus. This is of great surgical interest and will be discussed later. The main cause of death was hypoxaemia caused

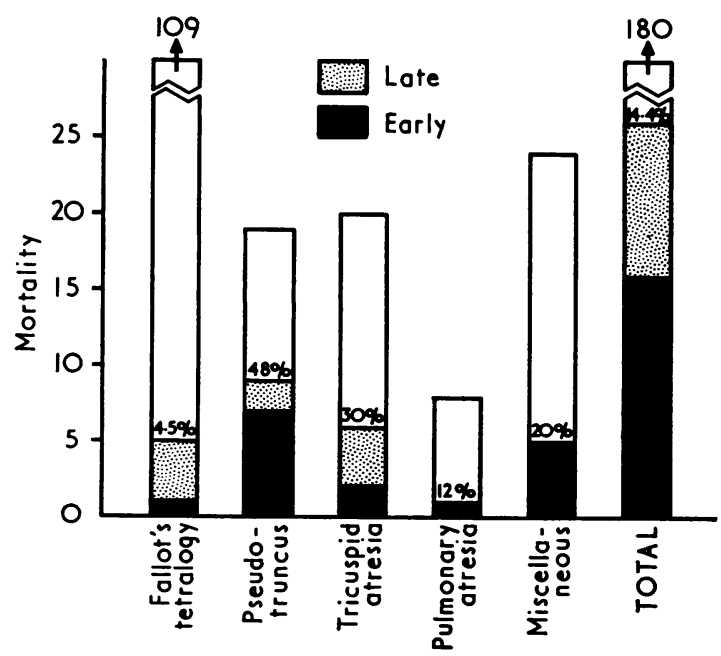

FIG. 2. See text. 


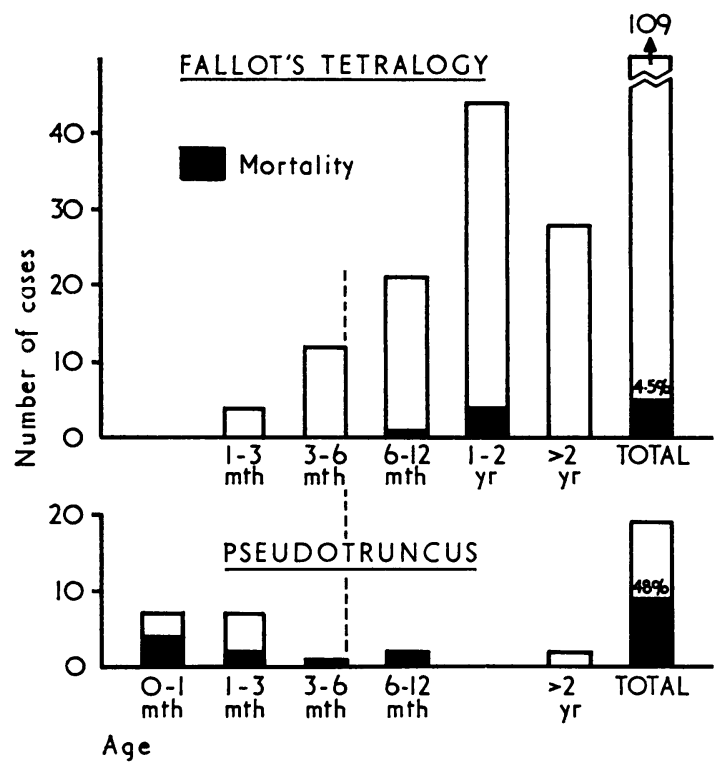

FIG. 3. See text.

T A B LE II I

EARLY MORTALITY

\begin{tabular}{l|c|l}
\hline \multicolumn{1}{c|}{ Cause of Death } & No. & \multicolumn{1}{|c}{ Diagnosis } \\
\hline Pulmonary oedema (large anastomosis) & 1 & Fallot's tetralogy \\
Anuria & 2 & Pseudotruncus \\
Hypoxaemia (acidosis) & 2 & Pseudotruncus \\
Bronchopneumonia (aspiration) & 1 & Tricuspid atresia \\
Cardiac arrest & 1 & Pseudotruncus \\
Enterocolitis & 3 & Milmonary atresia \\
At operation & 1 & Tricullaneous \\
& 2 & Pseudotruncus \\
& 2 & Miscellaneous \\
\hline & 16 & \\
\hline
\end{tabular}

T A B L E I V

LATE MORTALITY

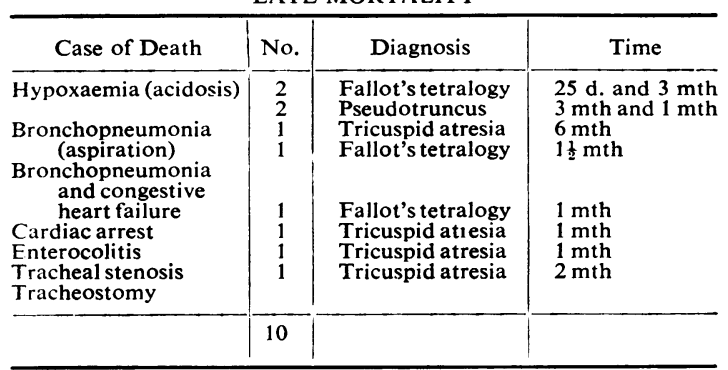

by insufficient blood flow, owing to the small diameter of the pulmonary arteries and also to the very acute condition of some patients.
Six deaths occurred among 20 patients with tricuspid atresia. Immediate deaths occurred in two cases, one from hypoxaemia and the other due to enterocolitis and pneumothorax. The other deaths are mentioned in Fig. 4 and Table III.

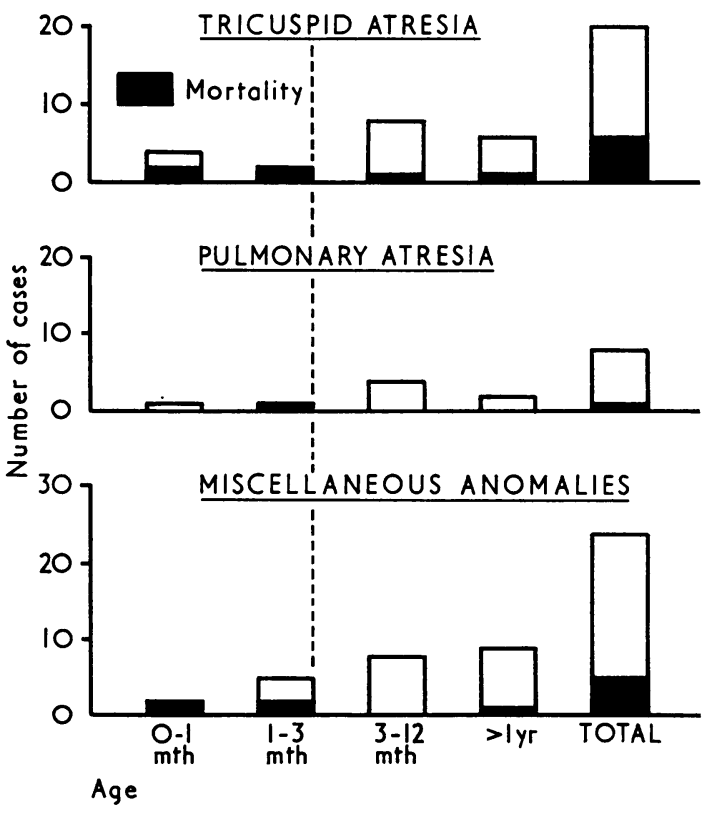

FIG. 4. See text.

At present, on patients under 2 years of age with tricuspid atresia we perform the Waterston operation. We take atrial pressures during the operation. If a gradient between the atria is found, we do a Blalock-Hanlon operation as well.

Of the 20 cases of tricuspid atresia in this report, 11 have been operated on with both techniques, and there were three deaths in this group (27\%). We think that with the combination of both methods, the results are superior in children under 2 years of age. In older children we prefer to use the Glenn operation.

For pulmonary atresia with intact septum, the Waterston technique has been performed on eight patients, with one death due to cardiac arrest at the time of operation.

To date, of the 180 patients operated upon with Waterston's technique only four have been reoperated for thrombosis at the anastomosis. A left Blalock-Taussig operation has been performed in two cases, a Potts and a total correction in the other two. 
The usual care given to critically ill cardiac patients was administered during the postoperative period, plus digitalization in all cases.

\section{DISCUSSION}

Although pseudotruncus is considered clinically as the extreme degree of Fallot's tetralogy, we separate this entity from Fallot because, from the surgical point of view, the problems to be considered are different, depending upon the diameter of the pulmonary arteries.

In emergency cases, and in patients with severe acidosis, we make the diagnosis according to the clinical findings without waiting for haemodynamic and angiographic studies. The main clinical findings are as follows: cyanosis at birth, lack of systolic murmur, pulmonary ischaemia, small heart, and an electrocardiogram characteristic of Fallot's tetralogy.

In 14 patients out of the 20 with pseudotruncus who were operated upon, the surgical operation was started without a haemodynamic study owing to the critical condition of the patients. With this method we could not exclude other associated malformations, especially a single ventricle. However, in all the patients who died, a correct clinical diagnosis was proved.

In three cases (not included in this report), the right pulmonary artery had a diameter of less than $2 \mathrm{~mm}$, which precluded any kind of anastomosis. In these cases treatment was confined to talc powdering of the right lung in order to create adhesions and to make possible the development of a collateral circulation from the thoracic wall and the mediastinum.

Of the 20 cases operated upon with Waterston's technique, five presented a right pulmonary artery diameter of about $3 \mathrm{~mm}$. Although we performed the operation, it was inadequate and the patients died of hypoxaemia and acidosis.

In these cases with pulmonary hypoplasia, we tried to create the fistula just at the level of the pulmonary artery bifurcation, as far as possible behind the aorta. At the same time we tried to avoid pulling on the pulmonary artery so as not to kink it, because this interferes with the even distribution of blood flow to both lungs. In these patients we did the anastomosis at the level of the bifurcation, thereby increasing the diameter of the pulmonary artery. There is no danger of an excessive blood flow because of the small diameter of the pulmonary arteries.

In patients with a diagnosis of pseudotruncus who have pulmonary arteries of less than $5 \mathrm{~mm}$ diameter, the large diameter of the aorta will cause the right pulmonary artery to kink if the anastomosis is not made at the pulmonary artery bifurcation. This occurred in $100 \%$ of cases. Because of this kinking, the flow will be preferentially or exclusively directed to the right lung.

We believe that the preferential blood flow to the right lung, observed with Waterston's technique and demonstrated by other authors, is due principally to a technical fault. If the fistula is made to the lateral wall of the aorta, a kinking of the pulmonary artery will be produced at the level of the anastomosis, with a preferential blood flow to the right lung. Another reason for this preferential blood flow is that excessive pulling of the right pulmonary artery produces a stenosis at the proximal end (Figs 5 and 6).

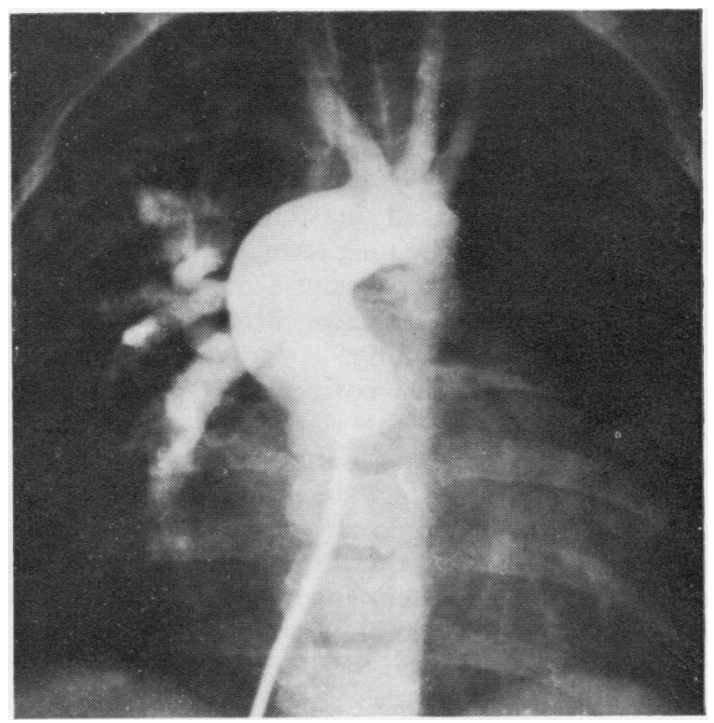

FIG. 5. Aortography in ascending aorta in a patient with Waterston's operation showing the preferential flow to the right lung.

Many problems associated with the classical techniques (Blalock-Taussig, Brock, and Potts) have been solved by the introduction of ascending aorta-right pulmonary artery anastomosis. This technique is simple, but it must be performed carefully, keeping in mind the possibility of the complications already described. We find that the main advantages are: $(a)$ the dissection is minimal; (b) the circulation to the arm remains normal; (c) the risk of thrombosis is lessened, especially in patients under 1 year of age ; and $(d)$ closure of the 


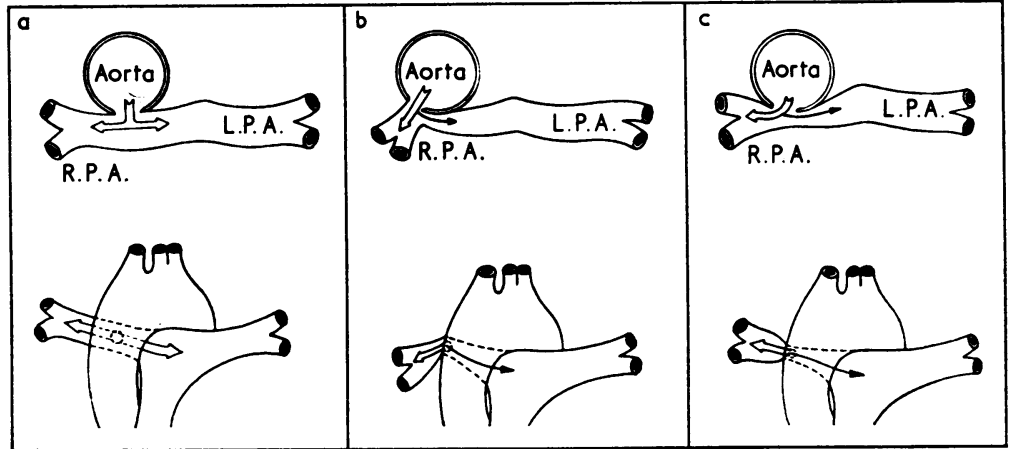

FIG. 6. (a) Ideal haemodynamic situation after Waterston's operation. (b) Preferential flow to right lung due to kinking of pulmonary artery. (c) Preferential flow to right lung due to stenosis caused by excessive pulling of the right pulmonary artery.

fistula will be simple when total correction is performed.

We consider the result to be good in those patients who progress with obvious clinical improvement and do not show cardiac failure caused by an enlarged anastomosis. However, we do not know if, in the long term, pulmonary hypertension might develop because of enlargement of the fistula, or, in other cases, because of preferential flow to the right lung.

At the time of total correction, when there is a preferential flow to the right lung, a peripheral stenosis of the right pulmonary artery at the level of the anastomosis may be found. This must be diagnosed and repaired. It must be considered a serious complication due to the posterior position of the pulmonary artery in relation to the ascending aorta which has to be approached by a median sternotomy used in the total correction.

\section{EXPERIMENTAL OBSERVATIONS}

As already stated, we believe that the preferential flow to the right lung, which appears in a high percentage of cases operated upon with Waterston's technique, is caused by either technical failure or haemodynamic turbulence caused by blood coming through the fistula and the flow from the main pulmonary artery.

We tried to prove this experimentally in dogs. If the anastomosis is not performed as far on to the posterior aspect of the aorta as possible, kinking occurs. The more lateral the anastomosis, the more acutely will the pulmonary artery be angulated (Fig. 7). This condition has been described by Somerville et al. (1969), who found that $50 \%$ of their cases had preferential flow to the right lung.



FIG. 7. Experimental aortography in the dog, showing preferential flow to the right lung when the anastomosis is made laterally in the aorta.

Even if the anastomosis is performed as far back as possible and in the correct place, but excessive $\underset{\mathbb{D}}{\stackrel{\circ}{D}}$

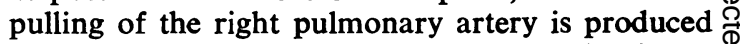
at the moment of clamping, then a proximal pul- $\varrho$ monary stenosis is created with preferential blood flow to the right lung (Fig. 8). 


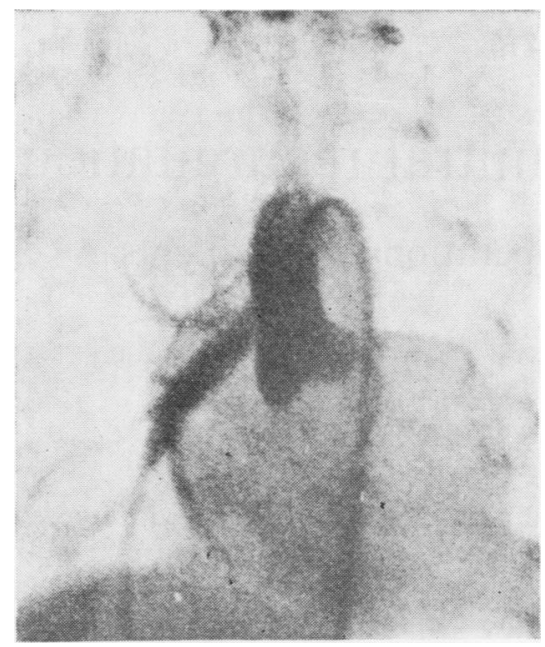

FIG. 8. Experimental aortography in the dog showing preferential flow to the right lung when the anastomosis is made in the posterior aspect of the aorta but with tension on the pulmonary artery.

We believe that the haemodynamic effect of the turbulence created by the new situation is important.

We are grateful to Mr. David Waterston, C.B.E., for the technical demonstration which he kindly performed in our department in November 1968.

\section{REFERENCES}

Albers, W. H., and Nadas, A. S. (1967). Unilateral chronic pulmonary edema and pleural effusion after systemicpulmonary artery shunts for cyanotic congenital heart disease. Amer. J. Cardiol., 19, 861.

Bernhard, W. F., Jones, J. E., Friedberg, D. Z., and Litwin, S. B. (1971). Ascending aorta-right pulmonary artery shunt in infants and older patients with certain types of cyanotic congenital heart disease. Circulation, 43, 580.

Blalock, A., and Taussig, H. G. (1945). Surgical treatment of malformations of the heart in which there is pulmonary stenosis or pulmonary atresia. J. Amer. med. Ass., 128, 189.
Brito, J. M., Quero, M., Lozano, C., Cordovilla, G., and Alvarez-Díaz, F. (1970). Tratamiento quirúrgico de las cardiopatias congénitas en niños menores de 2 años. Resultados en 226 casos operados. Bol. Soc. Pediat. Madr., 17, N-5.

Cooley, D. A., and Hallman, G. L. (1966). Intrapericardial aortic-right pulmonary arterial anastomosis. Surg. Gynec. Obstet., 122, 1084.

Edwards, W. S., Mohtashemi, M., and Holdefer, W. F. (1966). Ascending aorta to right pulmonary artery shunt for infants with tetralogy of Fallot. Surgery, 59, 316.

Pickering, D., Trusler, G. A., Lipton, I., and Keith, J. D. (1971). Waterston anastomosis. Comparison of results of operation before and after age 6 months. Thorax, 26, 457.

Potts, W. J., Smith, S., and Gibson, S. (1946). Anastomosis of the aorta to the pulmonary artery: Certain types in congenital heart disease. J. Amer. med. Ass., 132, 627.

Somerville, J., Yacoub, M., Ross, D. N., and Ross, K. (1969). Aorta to right pulmonary artery anastomosis (Waterston's operation) for cyanotic heart disease. Circulation, 39, 593.

Waldhausen, J. A., Friedman, S., Tyers, G. F. O., Rashkind, W. J., Petry, E., and Miller, W. W. (1968). Ascending aorta-right pulmonary artery anastomosis. Clinical experience with 35 patients with cyanotic congenital heart disease. Circulation, 38, 463.

Waterston, D. J. (1962). Treatment of Fallot's tetralogy in infants under one year of age. Rozhl. Chir., 41, 181.

\section{ADDENDUM}

Since this paper was submitted a further 25 patients have had a Waterston's anastomosis. Fifteen were under 1 year of age and 10 were older children. There was no mortality in the latter group and four died in the immediate postoperative period in the group under 1 year.

Of the 25 patients, 19 had a Fallot's tetralogy and were discharged from hospital in a good clinical condition. Three patients with a diagnosis of pseudotruncus were operated upon, one of whom died of hypoxaemia. In two cases of tricuspid atresia, a Blalock-Hanlon and a Waterston's procedure were performed at the same operation, and one patient aged 2 months died in anuria due to tubular necrosis following prolonged hypoxaemia and hypotension prior to the operation. The other six cases had miscellaneous heart anomalies and two patients died in the immediate postoperative period. 